\title{
СИСТЕМА МЕНЕДЖМЕНТА КАЧЕСТВА КАК ФАКТОР ПОВЫШЕНИЯ КОНКУРЕНТОСПОСОБНОСТИ ПРЕДПРИЯТИЯ
}

\section{QUALITY MANAGEMENT SYSTEM AS A FACTOR OF IMPROVEMENT ENTERPRISE COMPETITIVENESS}

L. Shvedov

Summary. The article discusses current issues related to the introduction of a product quality management system at enterprises, which is one of the key factors for ensuring the competitiveness of business entities. In the process of research, the principles of the formation of a quality management system at an enterprise are formalized. An algorithm for the development and implementation of the management system under consideration, consisting of three stages, is also proposed. Special attention is paid to problems on which special attention should be paid to enterprises for the further development and improvement of quality management systems.

Keywords: quality management, enterprise, products, algorithm.
Шведов Лев Александрович

К.и.н., доцент, Российский университет транспорта, г. Москва don.honda@mail.ru

Аннотация. В статье рассматриваются актуальные вопросы, связанные с внедрением системы менеджмента качества продукции на предприятиях, которая является одним их ключевых факторов обеспечения конкурентоспособности субъектов хозяйствования. В процессе исследования формализованы принципы формирования системы управления качеством на предприятии. Также предложен алгоритм разработки и внедрения рассматриваемой системы менеджмента, состоящий из трех этапов. Отдельное внимание уделено проблемам, на которых следует сосредоточить особое внимание предприятиям для дальнейшего развития и совершенствования систем управления качеством.

Ключевые слова: менеджмент качества, предприятие, продукция, алгоритм.

высокого уровня своей конкурентоспособности. Успешный мировой опыт свидетельствует, что именно система управления качеством является тем фактором, который позволяет формировать не только конкурентоспособность продукции, но и создавать уникальные преимущества системы управления предприятием, а также обеспечивать предпосылки для его устойчивого развития.

В соответствии с международными стандартами ISO 9000 система управления качеством является общепризнанным в мире механизмом, который обеспечивает высокие стандарты процессов, работ и услуг [2]. Введение таких систем должно быть стратегическим решением каждого предприятия.

Учитывая вышеизложенное, в последнее время руководство многих предприятий столкнулось с необходимостью управления качеством как средством достижения конкурентоспособности и эффективным методом завоевания доверия потребителей. Понятие «менеджмент качества» охватывает различные аспекты общей функции управления такие как постановка целей, определение ответственности, а также планирование, обеспечение и улучшение качества. 
Исходя из этого, исследование проблемы создания и внедрения системы управления качеством, которая являются одним из ключевых факторов в повышении конкурентоспособности предприятия, является актуальной и своевременной научно-практической задачей.

Актуальные проблемы управления качеством, различные аспекты формирования и внедрения систем качества на предприятиях рассматривались в трудах как отечественных авторов, так и зарубежных специалистов. В частности, среди них можно выделить: К. Исикаву, Э. Деминга, Дж. Джурана, Ф. Кросби, И. Кондо, Я. Мондена, В. Вахрушева, И. Исаева, Д.Г. Гольцева, Є. А. Гончарова.

Теоретические основы качества как научной категории, а также методологические подходы к организации систем управления качеством составляют предмет исследований многих современных авторов, к числу которых относятся: Г.А. Швиданенко, С. К. Фомичева, А.И. МоMOT.

В. Г. Версан, Е. Е. Парфенова, М. В. Сильникова, Д. Джураев рассматривают роль высшего руководства предприятия в создании и функционировании систем управления качеством.

Однако с течением времени и в контексте достижений научно-технического прогресса сущность и значение понятия управления качеством продукции меняется и корректируется, что обуславливает необходимость своевременного выявления проблем внедрения соответствующей системы менеджмента на предприятии с учетом текущих условий хозяйствования.

Малоисследованными помимо этого остаются вопросы построения систем управления качеством на предприятиях в соответствии с требованиями и критериями международных стандартов ISO 9000, а также способы обеспечения их эффективного функционирования.

Отдельного внимания заслуживают схемы организации подготовительных работ по внедрению систем управления качеством.

Таким образом, с учетом вышеизложенного, цель статьи заключается в изучении особенностей современных систем управления качеством на предприятиях, выступающих фактором повышения их конкурентоспособности, с учетом актуальных вызовов рынка и достижений мировой практики хозяйствования.

Передовая практика работы успешных мировых компаний позволили сформировать не только общие признаки систем управления качеством на предприятиях, но также принципы и методы, которые могут применяться в каждой из них. Главная целевая установка внедряемых систем - это обеспечение требуемого клиентом уровня качества продукции и предоставление ему доказательств способности предприятия этого достичь [3].

Итак, управление качеством продукции представляет собой целенаправленное воздействие на участников совместного трудового процесса с целью достижения ими надлежащего качества выпускаемой продукции. Такое управление охватывает функциональные отношения между двумя подсистемами - руководящей и управляемой. Следовательно, качество продукции является объектом управления при разработке требований, непосредственно к ней самой, а также к процессам ее проектирования, испытания, производства и эксплуатации. В конечном итоге сам процесс управления сводится к воздействию на совокупность свойств продукции или на отдельные ее качества, которые обусловливают ее пригодность и способность удовлетворять определенные требования в соответствии с назначением и рыночной конъюнктурой.

По мнению автора, внедрение системы управления качеством на предприятии, которая способна повысить его конкурентоспособность на рынке, должно базироваться на следующих принципиальных положениях:

1. Удовлетворение запросов потребителей. Главной целью внедрения системы менеджмента качества является ориентация деятельности персонала предприятия на удовлетворение потребностей клиентов. Это может быть достигнуто за счет реализации корпоративной политики, которая будет способствовать наиболее полному пониманию требований и вкусов потребителей. На практике запросы рынка рассматриваются в самом широком аспекте с учетом всех свойств продукции и связанных с ней услуг, которые могут влиять на удовлетворенность клиентов. Требования рынка должны определяться и идентифицироваться путем анализа заказов в соответствии с действующими на предприятии нормативными актами. Одним из таких документов может является Положение о сквозной системе управления контрактами, финансами и поставками продукции.

2. Документарное обеспечение функционирования системы менеджмента качества на предприятии. Перечень и содержание документации системы управления качеством определяется руководством предприятия с учетом положений соответствующих международных стандартов. Документация системы менеджмента качества может быть представлена такими видами документов: политика в области качества; цели и базовые 
принципы развития предприятия; руководство по качеству продукции; нормативные акты (стандарты СМК, положения); записи (протоколы качества); стратегические карты.

Руководство по качеству является одним из основных документов системы менеджмента качества, который позволяет сформировать общее представление о системе. Руководство обычно включает базовые принципы и политику в области качества, а также описание процессов системы менеджмента качества, их взаимосвязь, правила осуществления на предприятии.

3. Проведение регулярных внутренних аудитов (проверок) функционирования системы менеджмента качества. В соответствии с требованиями стандартов ISO серии 9000 все бизнес-процессы в системе управления качеством должны быть настроены и описаны таким образом, чтобы их можно было проверить.

Динамичность и постоянное повышение требований к качеству продукции обусловливают необходимость применения системного подхода к построению соответствующей системы менеджмента, который позволит учитывать взаимосвязи между субъектами и объектами управления качеством, исследовать закономерности их изменения, обеспечивать комплексное воздействие на характеристики и уровень качества. В связи с этим актуальной задачей является обоснование алгоритма разработки и внедрения системы управления качеством продукции на предприятии для обеспечения выполнения ею своего функционального назначения.

Представляется, что в рамках рассматриваемого алгоритма целесообразно выделить три этапа.

На начальном этапе происходит формализация основных ключевых аспектов будущей системы качества это планирование качества продукции и всех процессов, действующих на предприятии. Предприятию на данном этапе следует провести:

- нормирование требований к качеству продукции и процессов;

- определение качественных и количественных показателей развития предприятия, которых оно планирует достичь в ближайшей перспективе;

- определение эффективных методов контроля качества продукции и процессов.

Второй этап развития системы управления качеством заключается в обеспечении стабильного качества продукции на каждом этапе производства. Кроме того, этот этап предусматривает идентификацию отклонений от установленных требований и принятие дальнейших мер по предотвращению появлению повторных несо- ответствий путем своевременного применения корректирующих мер. Другими словами, основной задачей на данном этапе является - предупреждение и недопущение возможных нарушений установленных норм для обеспечения стабильного качества конечного продукта. На данном этапе большинство предприятий внедряют и сертифицируют систему управления качеством.

Заключительным и основным, по мнению автора, этапом в цепочке формирования действенной системы управления качеством, является постоянное ее улучшение и совершенствование, которое позволит поддерживать и наращивать конкурентоспособность предприятия на рынке.

Построенная таким образом интегрированная система управления качеством продукции станет адаптивной, гибкой, согласованной рабочей структурой предприятия, которая будет включать оптимальные технические и управленческие методы для обеспечения высоких результатов труда, наиболее эффективные способы взаимодействия людей и техники, кроме того, она будет способна генерировать всю информацию относительно качества продукции и производственного процесса, с целью удовлетворения запросов клиентов и требований партнеров.

Таким образом, подводя итоги проведенному исследованию, можно сделать следующие выводы. Внедрение на предприятиях современных и гибких систем управления качеством в соответствии с международными требованиями будет способствовать выпуску высококачественной и безопасной продукции, что соответственно позволит субъекту хозяйствования достигать высокой конкурентоспособности на рынке.

Вместе с тем, следует отметить ряд проблемных вопросов, на которых следует сосредоточить особое внимание руководству предприятия для дальнейшего развития и совершенствования систем управления качеством.

Главными из них являются:

- постоянный контроль и повышение требований к качеству сырьевых материалов;

- формирование понимания у персонала всех уровней необходимости внедрения современных методов управления качеством, изменение психологии сотрудников и их отношения к проблеме постоянного обеспечения высоких стандартов готовой продукции;

- постоянное обеспечение подготовки и повышения квалификации персонала;

- использование в производстве новых, современных технологий, материалов и оборудования. 


\section{ЛИТЕРАТУРА}

1. Зайченко И.М., Говоруха Е.Д. Система менеджмента качества как инструмент достижения стратегических целей на современных производственных предприятиях // Colloquium-journal. 2019. № 20. C. 5-10.

2. Кузнецова Ю. А. Необходимость внедрения системы менеджмента качества на предприятии // Студенческий. 2020. № 4-2(90). С. 47-48.

3. Санталова М.С. Система менеджмента качества коммерческого предприятия // Экономика и предпринимательство. 2019. № 1. С. $1150-1156$.

4. Тасболатова А. А. Совершенствование системы менеджмента качества на предприятии // Colloquium-journal. 2019. № 11-1(35). C. 145-147.

5. Соколова Т.Б., Игольник О. В. Система менеджмента качества предприятия. новые стратегии обеспечения конкурентоспособности предприятия // Научный аспект. 2019. Т. 7. № 1. С. 835-839.

( ) Шведов Лев Александрович ( don.honda@mail.ru).

Журнал «Современная наука: актуальные проблемы теории и практики»

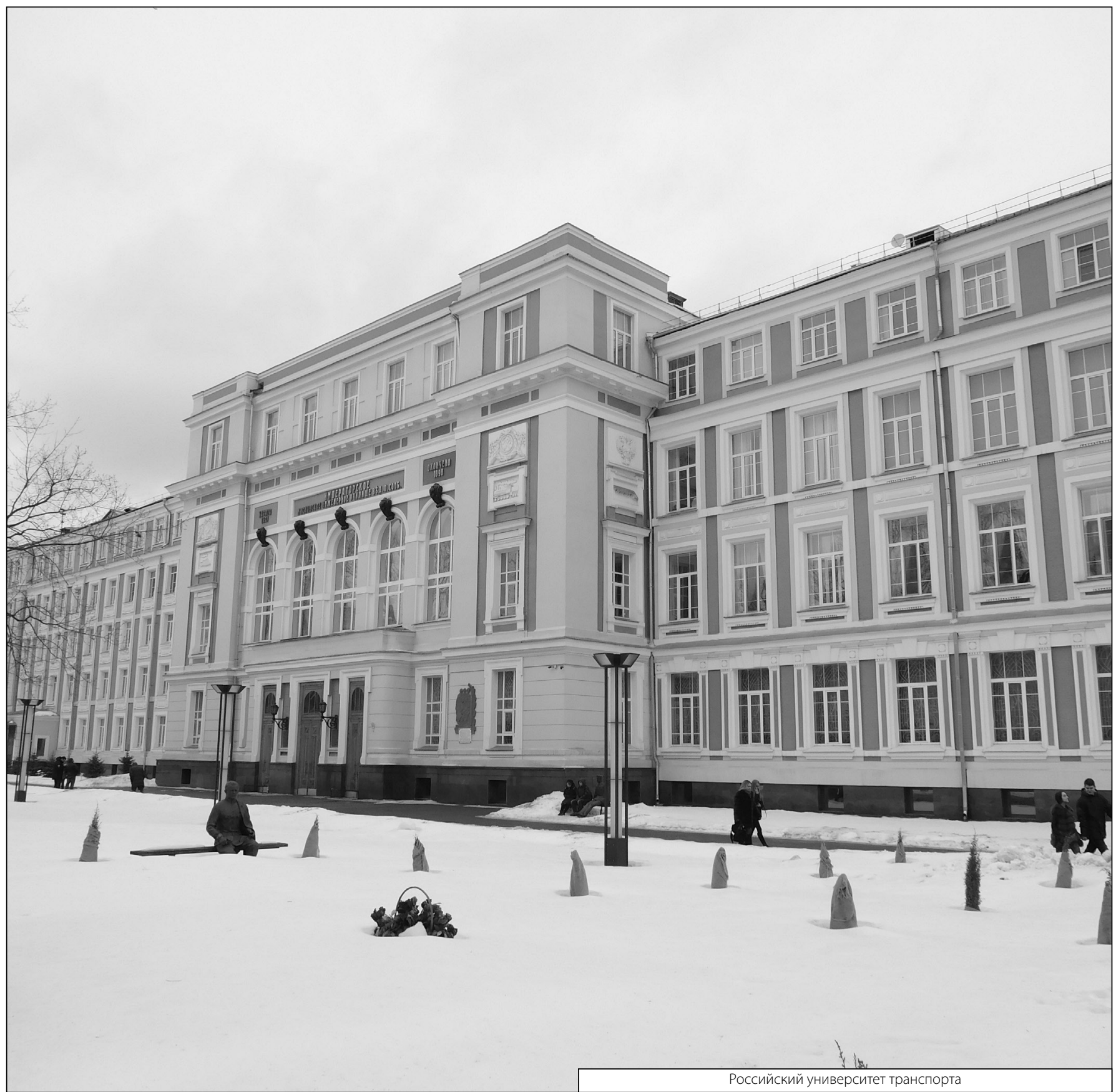

